will be very great. In terms of relief of human and animal distress and suffering, the recompense will scarcely be measurable.

${ }^{1}$ Hobson, A. D., Parasit., 38, 183 (1948).

2 Read, C. P., jun., Rice Institute Pamphlet, 37, No. 2 (1950).

${ }^{3}$ Smyth, J. D., Biol. Rev., 22, 214 (1947).

"Wardle, R. A., "The Physiology of Tapeworms". Manitoba Essan (Toronto, 1937).

s Lwoff, A., el al., "Biochemistry and Physiology of Protozoa", vol. 1 (Academic Press, Inc., NeW York, 1951).

${ }^{6}$ Lapage, G., Pub. Imp. Bur. of Agric. Parasit. (St. Albans, 1935).

"Lapage, $\boldsymbol{F}_{.}$, "Nematodes Parasitie in Animals" (Methuen and Co. Ltd., Jondon, 1937 ).

\section{ADVANCES IN MEDICINE}

Annual Review of Medicine

Windsor C. Cutting (editor), Henry W. Newman (associate editor). Vol. 2. Pp. $\mathrm{x}+485$. (Stanford, Calif. : Annual Reviews, Inc., 1951.) 6 dollars.

$\mathrm{N}$ this publication, twenty-six contributors under the editorship of Cutting and Newman review the advances made during the past two or three years in a wide variety of medical topics. There are nineteen sections in the book, the last being an annotated list of such review articles as appeared in the major redical journals during 1950.

The several authors show a considerable diversity of approaches in the presentation of their subjects, and not all are equally successful in securing clarity. The opening chapter, by Burnet, on virus and rickettsial diseases, is an excellent beginning to the book. It is at once readable, informative and well but not excessively documented - there are 136 references in twenty pages of text. Attention has been chiefly confined to advances significant for clinical medicine and public health, and the subjects discussed include the use of antibiotics in rickettsial and virus diseases, recent work on poliomyelitis, influenza, rubella in pregnancy, $Q$-fever, and the Coxsackie viruses.

Grimson and Howe, who review gastro-intestinal tract diseases, approach the subject from a surgeon's point of view. The presentation is far from lucid, however, and apart from the encouraging results attributed to Banthine ( $\beta$-diethylaminoethylxanthene9-carboxylate-methobromide) in disorders ranging from peptic ulcer, osophageal stricture and hiatus hernia to diverticulitis, ulcerative colitis and pancreatitis, there is little major progress recorded.

Diseases of the cardiovascular system are reviewed by Page and Corcoran, and this section is one of the most disappointing in the book. It certainly contains a host of recent references-338 in thirty-one pages of text-but the text to these references is extremely brief and frequently quite uninformative. The authors have assumed a knowledge of cardiovascular research on the part of the reader which few general physicians are likely to possess, and this chapter is consequently far too concentrated and technical for any but a specialist in cardiovascular diseases in search of references. Nesbit and Lapides provide a reasonable and readable evaluation of reports on tuberculosis and other infections of the urinary system, nephrolithiasis and'neoplasms of kidney and bladder. An excellent and well-balanced review of the coagulation problem and hæmorrhagic diatheses and disorders of leucocytes is contributed by Finch. The general physician may perhaps feel that this section, too, is somewhat over-documented and technical, but the field covered is small and the references come in a logical sequence. Meiklejohn and Passmore confine their attention, among nutritional topics, to kwashiorkor, famine and ascorbic acid metabolfsm, and under the heading of allergy Rose has dealt with the relationship of the pituitary adrenal mechanism to hypersensitivity. Both these sections, and particularly the latter, are most informative and clearly written.

The chapters on the reproductive system, the nervous system, psychiatry and the respiratory system are adequate reviews which the authors wisely confine to a few specific topics in each of the fields. The traumatic effects of stress and physical agents are well discussed by Behnke. Garland's section on radiology contains much interesting material but is marred by the fault, common to so many contributors in this work, of quoting too wide a bibliography with the minimum of textual reference. In a chapter on laboratory aids to diagnosis and therapy, Peters reviews only topics in which his own experience has been considerable. They include much research on serum content of precipitable iodine, lipids and proteins, measurement of body-fluid volumes and renal clearances. Scholtz and Williamson stress the growing appreciation of the close relation between skin disease and internal medicine and review progress in fields where this relationship is conspicuous.

Selye contributes an essay on the general adaptation syndrome which provides an admirable summary of his own work and views on this subject. He does not attempt to cover all recent work in this field, and the twenty-two references are all to the author's own publications. Aub and Nathanson summarize the clinical and experimental work done with adrenotropic hormone and cortisone in neoplastic conditions and conclude that these drugs affect the environment of the tumour rather than the growth itself. Kuzell has limited his contribution on diseases of bones and joints to rheumatoid arthritis and gout, and his review of the work ons these subjects is most valuable. There is a full discussion of the use of adrenotropic hormone and cortisone in these diseases.

The content of this book may be summarized as a laudable attempt to perform an impossible task.

\section{LIONEL WHITBY}

\section{JACOBSON'S ORGAN}

\section{Ouvrages sur l'organe voméro-nasal}

Par Louis Jacobson. Avec préface et notes par O. C. Hollnagel-Jensen et Dr. Erik Andreasen. Pp. xxxi+ 175. (Copenhague : Einar Munksgaard, 1948.) $30 \mathrm{kr}$. I OUIS LEVIN JACOBSON, having so far escaped Ld the inquisitive attentions of the denigrator, enjoys the unusual distinction of having actually discovered the vomeronasal sense organ of vertebrates with which his name is associated. Its duct, however, the nasopalatine canal or Stensen's foramen incisivum (canalis incisivus), had been seen by Vesalius in the dog and horse, and, apparently, in its vestigial state, in man himself. This Vesalian observation, which is described on p. 54 of the 1543 "Fabrica" and on p. 67 of the 1555 edition, is not correctly quoted in Cuvier's report reprinted in the present volume. Jacobson's organ in its most highly developed condition, as exemplified in some reptiles ${ }^{1}$, is in communication with the nasal cavity, and secondarily also with the buccal cavity by the incisive or nasopalatine canal. Jacobson was the first to 